\title{
Los créditos legalmente pospuestos en la Ley 20.720
}

\author{
Juan Luis Goldenberg Serrano*
}

\begin{abstract}
RESUMEN
Una de las novedades de la Ley 20.720, de reorganización y liquidación de activos de empresas y personas, consiste en la identificación de un número de créditos que, por diversos motivos, resultan degradados en sus posibilidades de pago, bajo la lógica de la posposición legal. El presente trabajo tiene por objeto conceder una primera mirada a esta regulación, a fin de identificar las razones para dicha opción legislativa, diferenciándola de la subordinación voluntaria prevista en el artículo 2489 CC, al tiempo que se pretende enmarcarlas en el elenco de normas que componen las reglas de prelación de créditos y explorar su lógica y características en el contexto de nuestro sistema concursal.
\end{abstract}

Subordinación de créditos - prelación de créditos - derecho concursal

$$
\text { Legal subordination in Act 20,720 }
$$

\begin{abstract}
One of the novelties of the Act 20,720, of reorganization and liquidation of assets of enterprises and individuals, is the identification of a group of credits that, for different reasons, are degraded in their possibilities of payment, under the logic of a legal subordination. This article aims to grant a first look to such regulation, purporting to identify the reasons for this legal option, separating it from the voluntary subordination recognized in article 2489 of the Chilean Civil Code, to locate them in the context of the several rules that create a ranking of claims and to explore its logic and characteristics in the grounds of the Chilean insolvency regime.
\end{abstract}

Subordination of claims - ranking of claims - insolvency law

* Licenciado en Ciencias Jurídicas y Sociales de la Pontificia Universidad Católica de Chile. Abogado. Doctor en Derecho, Universidad de Salamanca. Profesor de Derecho Civil de la Facultad de Derecho de la Pontificia Universidad Católica de Chile. Correo electrónico: jgoldenb@uc.cl. Este trabajo se inscribe en el proyecto Fondecyt Regular No 1150182 ("La subordinación legal de créditos en la nueva legislación concursal”). Artículo recibido el 26 de marzo de 2015 y aceptado para su publicación el 28 de agosto de 2015. 


\section{INTRODUCCIÓN}

$\mathrm{E}$ 1 tratamiento privilegiado se enmarca en un procedimiento en que ha quedado en evidencia la insuficiencia de los bienes del deudor para dar respuesta a todas sus relaciones crediticias, pero debe tener un carácter excepcional a efectos de no alterar las bases de la concursalidad y la correcta valoración del riesgo de insolvencia ${ }^{1}$. En el contexto del Derecho comparado, la revisión de las normas de prelación de créditos no solo se han detenido en el adelgazamiento de la tutela preferencial ${ }^{2}$, sino que también en la posibilidad de que ciertos créditos resulten minusvalorados en el campo del conflicto de acreedores ${ }^{3}$. La minusvaloración, en todo caso, es apreciada desde la lógica concursal, en que, por razones de justicia distributiva, y funcionales a los fines del concurso, pueden identificarse ciertos elementos constitutivos del crédito o conductuales de su titular que resultan relevantes para generar un nuevo tipo de norma de graduación, en este caso, negativa.

Dicha clase de créditos suele designarse bajo el concepto de la subordinación ${ }^{4}$, haciendo uso de la nomenclatura con la que ella nace terminológicamente en el Derecho

${ }^{1}$ Tanto los ordenamientos jurídicos continentales (por todos, Garrido, J.M., Tratado de las preferencias del crédito, Civitas, Madrid, 2000, p. 120), como aquellos basados en el Common Law (por todos, Goode, R., Principles of corporate insolvency law, Sweet \& Maxwell, Londres, 2011, p. 99) establecen la regla de distribución proporcional como norma general de coordinación. Su permanencia temporal y consagración en la mayoría de las legislaciones puede dar la idea de estar frente a la única solución al problema de concurrencia de los acreedores ordinarios, sobre la base de nociones de igualdad de trato, justicia y equidad en el reparto de cargas. Nos parece, sin embargo, que dicha opción ha nacido de una decisión legislativa basada en el carácter escasamente público de las relaciones crediticias, de manera que no existe verdadera información sobre su existencia a efectos de ponderar el riesgo al que se accede al tiempo de contratar, evitando la aplicación de la fórmula de temporalidad (prior in tempore, potior in iure), que sí es admisible en lo relativo a las garantías reales (Goldenberg Serrano, J.L., "Consideraciones críticas respecto al denominado principio de la par condicio creditorum”, en Revista Chilena de Derecho, Vol. 37, No 1, 2010, p. 82).

${ }^{2}$ En España, por ejemplo, el apartado V de la Exposición de Motivos de la Ley No 22/2003, concursal, justificaba la poda de los privilegios, ante evidencias, como las señaladas por Beltrán Sánchez, E., "El nuevo Derecho concursal español”, en Anales de la Academia Matrisense del Notariado, No 43, 2007, pp. 487 y 488 , en que "La escasa satisfacción de los acreedores -ordinarios- deriva, en fin, de la existencia de numerosos créditos privilegiados, que se han ido acumulando a lo largo de la historia, introduciéndose en función de las presiones de los correspondientes grupos sociales". O, en Alemania, en que -con un diagnóstico concordantese suprimieron todos los privilegios legales en sede concursal (Schmidt, K. "Fundamentos del nuevo Derecho concursal alemán”, en García Villaverde, R.; Alonso Ureba, A.; y Pulgar Ezquerra, J. (dirs.), Estudios sobre el Anteproyecto de la Ley Concursal de 2011, Dilex, Madrid, 2002, p. 27).

3 Ávila de la Torre, A., "La subordinación en el concurso de los créditos de las personas especialmente relacionadas”, en Sarcina, A. y García-Cruces, J.A. (dirs.), Il trattamento giuridico della crisi d'impresa. Profili di diritto concorsuale italiano e spagnolo a confronto, Cacucci Editori, Bari, 2008, p. 159.

${ }^{4}$ En nuestro ordenamiento, como veremos más adelante, la voz "subordinación" ha quedado reservada para el tratamiento especial del crédito valista del artículo 2489 CC, incorporado por la Ley 20.190, de 2007, y de los bonos subordinados que pueden emitir los bancos al amparo del artículo 55 del D.F.L. N N $^{\circ}$, de 1997, que fija el texto de la Ley General de Bancos. 
norteamericano ${ }^{5}$, aun cuando diversos ordenamientos hayan reconocido la figura mediante denominaciones diversas, bajo las nociones análogas de "postergación” 6 , como en nuestro sistema jurídico, "posposición”. Dicha tendencia recibe ahora un reconocimiento expreso en la Ley 20.720, de reorganización y liquidación de activos de empresas y personas (LRAEP). Pero es importante señalar que, a diferencia de otros sistemas jurídicos ${ }^{7}$, la nueva regulación concursal no postula un tratamiento unitario de los "créditos legalmente pospuestos", al tiempo que escasamente advierte los puntos de contacto y la necesaria coordinación con la subordinación voluntaria reconocida en el artículo 2489 del Código Civil (CC), lo que dificulta la identificación de los fundamentos dogmáticos y de la fisonomía jurídica de dicha figura.

Pero creemos que, sin perjuicio de la formulación fragmentaria, puntual y desorganizada del tratamiento jurídico dado a los créditos legalmente subordinados en el Derecho nacional, igualmente pueden esbozarse elementos descriptivos para comprender su justificación, naturaleza y consecuencias jurídicas, lo que constituye la finalidad del presente trabajo. Obsérvese, sin embargo, que no es nuestra intención, por el momento, dar cuenta precisa de las particularidades de cada supuesto tipificado por la LRLAEP,

${ }^{5}$ Si bien existen antecedentes en el Partnership Act inglés de 1890, el establecimiento de la subordinación crediticia recoge como primer antecedente expreso el reconocimiento, primero jurisprudencial y luego legal, de la subordinación a nivel del artículo 510 del United States Code 11 (USC 11). Vid. Ferré Falcón, J., Los créditos subordinados, Thomson Civitas, Cizur Menor, 2006, pp. 126-163, y Vattermoli, D., Crediti subordinati e concorso tra creditori, Giuffrè Editori, Milán, 2012, pp. 96-110. Para un análisis particular de la teoría del equitable subordination, y su evolución histórica en el Derecho norteamericano, vid. Herzog, A.S. y Zweibel, Joel B., "The equitable subordination of claims in bankruptcy", Vanderbilt Law Review, Vol. 15, 1961, pp. 83-118; y Warren, W.D., Bussel, D.J. y Skeel, Jr., D.A., Bankruptcy, Foundation Press, Estados Unidos de América, 2012, pp. 431-454. A su vez, para efectos de conceder un marco de aplicación general a la subordinación equitativa, pueden consultarse las secciones 60 y 61 del Capítulo V de la Guía Legislativa de la CNUDMI sobre el régimen de la insolvencia.

${ }^{6}$ Denominación reconocida en el Derecho comparado, por ejemplo, en el artículo 2.467 del Codice Civile italiano, producto de la reforma societaria del año 2003, y el artículo 69 de la Ley 1.116, de Insolvencia Empresarial colombiana, de 2006, y que originalmente se encontraba en los artículos 139 y 240 del proyecto de ley contemplado en el Mensaje presidencial que dio inicio a la tramitación de la LRLAEP (Historia de la Ley 20.720, pp. 67 y 95). La voz "postergados" fue posteriormente reemplazada por la de "pospuestos" (Historia de la Ley, Segundo Informe de las Comisiones Unidas, pp. 1.045 y 1.088), probablemente para conservar una unidad terminológica.

No obstante, a nivel comparado generalmente se utiliza la voz "subordinación" para abordar este efecto. Por ejemplo, el artículo 510 USC 11; el artículo 92 de la Ley 22/2003, concursal de España (LC); el artículo 46 del Código da Insolvência e Recuperação de Empresas portugués, de 2004; el artículo 83 de la Ley 11.101 de recuperaçao judicial, extrajudicial e falencia brasileña, de 2005; el artículo 111 de la Ley 18.387, de declaración judicial del concurso y reorganización empresarial uruguaya, de 2008; y el artículo 222 bis de la Ley de Concursos Mercantiles mexicana, de 2000, conforme a la reforma incorporada el 10 de enero del presente año, entre otros. En el Derecho alemán, por su parte, la identificación de la figura se efectúa sobre la idea de la pérdida del rango (nachrangige Gläubigern), reconociendo un catálogo de tales créditos en la $\$ 39$ de la Insolvenzordnung, de 1999 ("InsO"). La identidad de todos estos términos es expuesta, por ejemplo, por Vattermoli (n. 5), p. 3.

${ }^{7}$ La mayor parte de los cuales es referido en la cita número 6. 
aunque debamos hacer referencia a algunas de sus normas en particular a fin de cumplir con el objetivo propuesto ${ }^{8}$.

A estos efectos, el presente trabajo se articula del siguiente modo: en primer lugar se examinarán los paralelos y diferencias entre las reglas de degradación propuestas para la subordinación voluntaria y los créditos legalmente pospuestos; luego se revisará la forma en que creemos puede incardinarse este grupo de normas en el contexto de aquellas que regulan la prelación de créditos; y, finalmente, se abordará su dimensión concursal, con el objeto de advertir sus principales características sobre la base de algunas notas comunes de su régimen jurídico.

\section{LA SUBORDINACIÓN VOLUNTARIA COMO MODELO DE POSPOSICIÓN CREDITICIA Y SUS DIFERENCIAS CON EL CRÉDITO LEGALMENTE POSPUESTO}

Bajo una conceptualización más moderna de la posposición crediticia ${ }^{9}$, nuestro ordenamiento había reconocido la admisibilidad general y efectos de la subordinación voluntaria por medio de su incorporación en el artículo 2489 CC $^{10}$. La creación de la figura de los créditos legalmente pospuestos en la LRLAEP, sin embargo, no obedece a iguales justificaciones y expedientes técnicos, conclusión a la que ha llegado la doctrina extranjera ${ }^{11}$, aun en los casos en los que ambas figuras (subordinación voluntaria e involuntaria) se encuentran reguladas en una misma disposición o, incluso, integradas a una única categoría jurídica ${ }^{12}$. No obstante, el punto de contacto entre ambas figuras se encuentra en su efecto primordial, como es el ofrecer una regla de graduación de los créditos que logra un descenso en la escala de prelación de créditos ${ }^{13}$.

${ }^{8}$ Nos referimos a los supuestos contemplados en los artículos 57.1.c), 63, 139, 241, 264.4 y 292 LRLAEP.

9 En nuestro ordenamiento, algún antecedente, aunque no bajo la nomenclatura de la posposición o subordinación, puede encontrarse en el artículo 67 de la Ley 18.045, de mercado de valores, en la que se dispone que en caso de un procedimiento concursal de liquidación de un emisor de valores, los créditos de los terceros acreedores de la sociedad prevalecerán sobre los que posean los socios de la entidad emisora en contra de esta proveniente de una disminución de capital, y, como veremos más adelante, en el tratamiento de los intereses devengados una vez declarada la quiebra, conforme al antiguo régimen concursal dispuesto en la Ley 4.558, de 1929.

${ }^{10}$ Sin embargo, previo a dicha modificación, incorporada por la Ley 20.190, de 2007, nuestro ordenamiento jurídico reconocía la subordinación en términos muy limitados, solo contando con una referencia expresa en la Ley 18.818, de 1 de agosto de 1989, en el marco de las reglas de adecuación de capital de las entidades bancarias. Sobre el particular, vid. Ugarte Godoy, J.J., "Sobre la posibilidad de pactar que una obligación tenga el carácter de subordinada en el Derecho chileno”, en Varas Braun, J.A. y Turner Saelzer, S. (coords.), Estudios de Derecho Civil, Lexis Nexis, Santiago, pp. 374 y 376-380.

${ }^{11}$ Por todos, Bermejo Gutiérrez, N., Créditos y quiebra, Civitas, Madrid, 2002, p. 436.

12 Por ejemplo, para el ordenamiento español, en la lectura del artículo 92 LC, vid. Montés Penadés, V.L., "El régimen de los créditos subordinados en la Ley concursal", Anuario de Derecho Concursal, No 1, 2004, p. 58; y Valpuesta Gastaminza, E., “Artículo 92”, en Cordón Moreno, F. (dir.), Comentarios a la Ley concursal, Thomson Aranzadi, Cizur Menor, 2004, pp. 732 y 734.

${ }^{13} \mathrm{O}$, como indica Ferri jr., G., "In tema di postergazione legale", Rivista del Diritto Commerciale e del Diritto generale delle obligazioni, Año CII, Nos. 10, 11 y 12, (2004), p. 970, lo anterior permite establecer 
Pero la marcada división entre uno y otro supuesto no solo se aprecia desde la fuente misma de la subordinación (voluntaria o legal), sino especialmente en su finalidad y tipicidad.

Respecto de lo primero, Vattermoli nos indica que la subordinación involuntaria pretende corregir las anomalías que, en virtud de la operación del sistema de graduación de crédito y en defecto de la regla postergatoria, determinaría una participación en el patrimonio del deudor de un crédito que no se considera meritorio de concurrir en igual plano que los demás créditos ${ }^{14}$. Por su parte, la subordinación voluntaria se enmarca necesariamente en una pretensión financiera ${ }^{15}$, identificada conforme al tenor del negocio jurídico que le sirve de fundamento ${ }^{16}$, bien para servir de un equivalente económico al capital (subordinación general) ${ }^{17}$, o bien para ser utilizada como una forma de garantía constituida a favor del acreedor beneficiario ${ }^{18}$. Lo anterior implica que detrás de la subordinación voluntaria no existe un juicio de valor por parte del ordenamiento jurídico que tenga por resultado el efecto degradatorio que le es propio ${ }^{19}$, ni que por medio de ella se pretenda ofrecer un mayor equilibrio en términos de justicia distributiva $^{20}$, características que sí pueden apreciarse en el caso de la posposición legal ${ }^{21}$.

Respecto de la tipicidad, las figuras también se plantean de modo diverso: la subordinación involuntaria requiere de una calificación previa por parte del ordenamiento, porque solo por medio de ella el legislador logra una identificación de las razones por las cuales justifica la inadecuación al caso de la regla de proporcionalidad que impera con eficacia general en el marco de la prelación de crédito $^{22}$. De tal suerte, operando

una cierta unidad del mecanismo de la subordinación (voluntaria e involuntaria), a partir del cual puede elaborarse una disciplina de la figura.

14 Vattermoli (n. 5), p. 10. En igual sentido, Valpuesta Gastaminza (n. 12), p. 731; Ávila de la Torre, A. y Curto Polo, M., "La subordinación del crédito de las personas especialmente relacionadas con el concursado, en Estudios sobre la Ley concursal: Libro homenaje a Manuel Olivencia, T. IV, Marcial Pons, Madrid, 2005, p. 3540; Ferré Falcón (n. 5), p. 27, con expresa referencia a la justicia distributiva como uno de los principios inspiradores del Derecho concursal, especialmente alusivo al antiguo reconocimiento de la tutela preferencial del crédito.

${ }^{15}$ En términos generales, Wood, P.R., The law of subordinated debt, Sweet \& Maxwell, Londres, 1990, pp. 2 y 3; Vanoni, S., I crediti subordinati (G.Giappichelli Editore, Turín, 2000, pp. 4-8; Bermejo Gutiérrez (n. 11), p. 436; y Ferré Falcón (n. 5), pp. 224-228.

${ }^{16}$ Guilarte Gutiérrez, V., "Artículos $92.1^{\circ}$ a $4^{\circ}$ y 60", en Sánchez-Calero, J. y Guilarte Gutiérrez, V. (dirs.), Comentarios a la Legislación concursal, Lex Nova, Valladolid, 2004, p. 2042.

${ }^{17}$ Goldenberg Serrano, J.L., La subordinación voluntaria de créditos, Civitas Thomson Reuters, Cizur Menor, 2011, pp. 63-102.

${ }^{18}$ Goldenberg Serrano (n. 17), pp. 102-128.

19 Ávila de la Torre y Curto Polo (n. 14), p. 3541.

${ }^{20}$ Sastre Papiol, S., "Artículo 92”, en Sagreda Tizón, J.M., Sala Reixacs, A., y Ferrer Barriendos, A., Comentarios la Ley concursal, Bosch, Barcelona, 2004, p. 1130.

${ }^{21}$ Ibáñez Jiménez, J., "Deuda subordinada, obligaciones subordinadas y reforma concursal”, en Créditos, garantías y concurso. Estudios jurídicos en homenaje al profesor Ruiz de Velasco, Civitas Thomson Reuters, Cizur Menor, 2010, p. 474.

${ }^{22}$ En nuestro ordenamiento, aunque referido a las preferencias crediticias, vid. Alessandri Rodríguez, A., La prelación de créditos, Editorial Nascimento, Santiago, 1940, p. 10; Bahamóndez Prieto, L.F., La prelación 
por vía excepcional, la interpretación de los supuestos contemplados en la LRLAEP deberá ser siempre restrictiva, al tiempo que tampoco deberá admitirse una aplicación analógica $^{23}$, del mismo modo que la extensión de sus consecuencias jurídicas estará dada imperativamente por el legislador, sin que sea posible a las partes alterar su contenido. Lo anterior se presenta de manera diversa en la subordinación voluntaria, ya que, en relación con la tipología del crédito, ella se presenta neutral ${ }^{24}$, con excepción de su calificación como crédito valista en los términos del artículo 2489 CC ${ }^{25}$. Así, la amplitud de los efectos del negocio de subordinación dependerá del contenido dado por su autor o por las partes, y, en su caso, por las reglas de integración contractual (artículo 1546 CC), sin perjuicio de las normas interpretativas dadas por el mismo legislador (por ejemplo, en materia de extensión a los intereses) ${ }^{26}$ y de su eficacia concursal (artículo 241 LRLAEP).

En consecuencia, pese al paralelismo que puede anotarse entre ambas figuras, especialmente en su calificación como crédito residual ${ }^{27}$, debemos insistir en sus diversas fisonomías jurídicas. Al respecto, si bien se han planteado un sinnúmero de teorías para

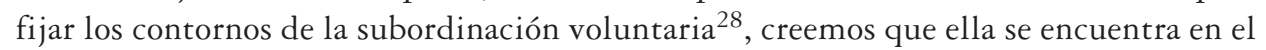
ejercicio de la autonomía privada aplicada a la posibilidad de la exclusión normativa ${ }^{29}$, allí donde la regla se nos presenta como dispositiva, como sostenemos ocurre con la regla de proporcionalidad dispuesta en el artículo 2489 CC $^{30}$. Como podrá observarse,

de créditos, Editorial Jurídica de Chile, Santiago, 1993, p. 38, y Abeliuk Manasevich, R., Las obligaciones, Tomo II, Legal Publishing Thomson Reuters, Santiago, 2014, p. 1150.

${ }^{23}$ En el mismo sentido se plantea en el Derecho español, vid. García Orejudo, R., "Créditos subordinados", en Nieto Delgado, C. (coord.), Derecho concursal, Tirant lo Blanch, Valencia, 2012, p. 471. En nuestro ordenamiento, debe llegarse a igual conclusión dada su calidad de norma de carácter excepcional, criterio empleado por nuestra jurisprudencia en el contexto de los privilegios (considerando sexto de la sentencia de la Corte Suprema, de fecha 29 de enero de 2015, en autos caratulados "Banco Santander Chile con Servicio de Tesorerías Regional de Aysén y otro”, rol 22.816-2014, disponible en la base de datos de Legal Publishing, bajo el código CL/JUR/479/2015).

${ }^{24}$ Veiga Copo, A. La masa pasiva del concurso de acreedores, Civitas Thomson Reuters, Cizur Menor, 2012, p. 1254.

${ }^{25}$ Goldenberg Serrano (n. 17), p. 186.

${ }^{26}$ Artículo 2.489, inciso quinto, parte final.

27 Bermejo Gutiérrez (n. 11), p. 435.

${ }^{28}$ En el ámbito del Derecho norteamericano, vid. Wood (n. 15), pp. 26 y 27; y en el contexto del Derecho continental, vid. Goldenberg Serrano (n. 17), pp. 185-244; y Vattermoli (n. 5), pp. 27-41.

${ }^{29}$ Para una referencia a la incidencia de la autonomía privada en el ámbito de la subordinación voluntaria, vid. Vanoni (n. 15), p. 2; Bermejo Gutiérrez (n. 11), p. 441; Alonso Ledesma, C., "Delimitación de la masa pasiva: las clases de crédito y su graduación”, en García Villaverde, R.; Alonso Ureba, A.; y Pulgar Esquerra, J., Derecho concursal. Estudio sistemático de la Ley 22/2003 y de la Ley 8/2003 para la reforma concursal, Editorial Dilex, Madrid, 2003, pp. 391 y 399; Garrido, J.M., “Artículo 92. Créditos subordinados”, en Rojo, A. y Beltrán, E., Comentarios de la ley concursal, Thomson Civitas, Cizur Menor, 2004, p. 1659; Guilarte Gutiérrez (n. 16), p. 2042-2045; Sastre Papiol (n. 20), p. 1134; Ferré Falcón (n. 5), p. 217 y Veiga Copo (n. 24), p. 1257.

30 Goldenberg Serrano (n. 17), pp. 222-247, explicación que es aceptada también por Veiga Copo (n. 24), pp. 1251 y 1254. La doctrina nacional escasamente se ha referido a la materia, aunque Abeliuk Manasevich (n. 22), p. 1212, expresa la idea de una "especie de cesión de créditos, solo que lo cedido no es la deuda, sino que la igualdad del Art. 2490 del C.C.”, propuesta que solo nos parece admisible en la medida que esté dando cuenta en términos meramente figurativos de la subordinación voluntaria. 
tal explicación no es admisible en el campo de la subordinación involuntaria, ya que esta en caso alguno dependerá de la voluntad del acreedor titular del crédito que resulta subordinado, sino que esta será impuesta desde el exterior de la relación crediticia ${ }^{31}$, especialmente, en el caso chileno, a partir de una disposición de rango legal. Lo anterior también implica que será el legislador quien señalará tanto los requisitos para que el crédito pueda ser calificado como pospuesto, como los efectos derivados de dicha posposición en el campo de su regulación concursal.

\section{LA SUBORDINACIÓN LEGAL EN EL ÁMBITO DE LA PRELACIÓN DE CRÉDitos}

\section{La tutela conflictual de los créditos y el binomio proporcionalidad/graduación}

La doctrina comparada ha reconocido una mayor proximidad de la técnica de la subordinación legal a la de los privilegios $\operatorname{crediticios~}^{32}$, idea que compartimos al tiempo que destaca la necesaria incardinación de la figura en el campo de la prelación de cré$\operatorname{ditos}^{33}$, y en consecuencia, en el ámbito de su tutela conflictual ${ }^{34}$. Luego, el punto de contacto entre privilegio y subordinación también se ofrece desde la lógica de su operatividad sustentada en los presupuestos básicos, como son la insuficiencia del producto de la ejecución patrimonial, la pluralidad de acreedores concurrentes y la existencia de una norma legal que atribuya directamente la preferencia (en este caso, la posposición) a uno de los acreedores ${ }^{35}$.

Adicionalmente, del mismo modo que los privilegios, la técnica se presenta a modo de identificar un catálogo heterogéneo de créditos que, a juicio del legislador, merecen un tratamiento diverso al que plantea la regla proporcional. Heterogeneidad que,

${ }^{31}$ Vattermoli (n. 5), p. 5.

${ }^{32}$ En este sentido, vid. Vattermoli (n. 5), p. 5. De hecho, es posible notar en la posposición legal similares características a las que conforman el privilegio crediticio, que, conforme explicita Gullón Ballesteros, A., La prelación de créditos en el Código Civil, Bosch, Barcelona, 1962, pp. 18 y 19, se basan en su legalidad, taxatividad, accesoriedad, interpretación estricta e indivisibilidad, particularmente al hacer referencia a los privilegios generales, características que son complementadas por Garrido (n. 1), p. 43 con su relatividad.

${ }^{33} \mathrm{Al}$ igual que en el caso del privilegio, se hace uso de una norma de carácter sustantivo, a efectos de darle aplicación en el campo que le es propio, como es aquel que hace operativas las reglas de prelación de créditos (Guizzi, G., "Il passivo”, Diritto Fallimentare (Manuale Breve), Giuffrè Editore, Milán, 2013, p. 301).

${ }^{34}$ La idea general de la tutela conflictual del crédito es conferida por Garrido (n. 1), p. 29, haciendo luego énfasis en que el privilegio se resuelve en un derecho que se ejerce, no frente al deudor, sino ante otros acreedores, denotando sus caracteres de relatividad (p. 456). Con el carácter de subordinación, vid. Ávila de la Torre y Curto Polo (n. 14), p. 3540; Migliaccio, E., Parità de trattamento e concorso dei creditori, Edizioni Scientifische Italiane, Nápoles, 2012, p. 71; y Bianchi, A., Fucito, M. y Gulotta, M., Postergazione, prededucibilità e pagamento dei crediti in regime di continuità aziendale. Il finanziamenti societari nella legislazione sulla crisi di impresa, Maggioli Editore, Santarcangelo di Romagna, 2013, p. 74. Las normas de prelación, ya había indicado Gullón Ballesteros (n. 32), p. 16, nos dé cuenta necesariamente de un conflicto de acreedores, en la que el privilegio se desenvuelve como una derogación a una norma de carácter general, como es aquella referida a la igualdad de todos los acreedores para efecto del cobro.

${ }^{35}$ Garrido (n. 1), p. 41. 
como apunta frecuentemente la doctrina comparada, permite concluir que no existe un principio común de subordinación, sino que cada supuesto se reflejará y encontrará su debida justificación en la tipología cerrada concebida por el propio legislador ${ }^{36}$, lo que impide conceder una definición unitaria de los créditos legalmente pospuestos si no es en razón "de su puro carácter postergado"37.

$\mathrm{Y}$, aun así, finalmente, suele plantearse en las antípodas del privilegio general ${ }^{38}$, como excepción negativa al principio de igualdad de trato ${ }^{39}$, o, derechamente, como "antiprivilegio". Se trata, en este caso, de configurar un crédito sobre la base de elementos que, racional y objetivamente, supongan la necesidad que el legislador minusvalore su participación en el concurso o que, observado desde la óptica de los demás acreedores, favorezca sus posibilidades de cobro ${ }^{40}$.

\section{La naturaleza jurídica de la subordinación legal}

Al tratar específicamente acerca del asunto de la naturaleza jurídica de la subordinación legal, Sebastián Quetglas nos informa que es probablemente este tema "el que ha dado lugar a un mayor número de opiniones divergentes entre los estudiosos en la materia”, aunque, en su caso, aboga por la oscura idea de la renuncia legal del rango en beneficio de los acreedores ordinarios y privilegiados ${ }^{41}$. E indicamos "oscura", por

${ }^{36}$ Por ejemplo, Garrido (n. 29), p. 1661; Ávila de la Torre y Curto Polo (n. 14), pp. 3539 y 3540 ; Ferré Falcón (n. 5), p. 29; Blasco Gascó, F. de P., El pago de los acreedores concursales, Aranzadi Thomson Reuters, Cizur Menor, 2010, p. 324; Veiga Copo (n. 24), pp. 1243 y 1245; Lüdtke, M., “\$39 InsO”, en Hamburger Kommentar zum Insolvenzrecht, Carl Heymanns Verlag, Colonia, 2012, p. 545; y Schmidt, K. y Herchen, A., “\$39 InsO”, en Schmidt, K. (dir.), Insolvenzordnung, C.K. Beck, Munich, 2013, p. 410.

37 Ferré Falcón (n. 5), p. 29, materia que retoma en p. 166, a efectos de indicar que la "categoría de créditos subordinados se puede definir como aquella integrada por una serie de créditos concursales de carácter heterogéneo, que comparten la característica de ser satisfechos por detrás de los créditos privilegiados y ordinarios y que están sometidos a un régimen de derechos más restrictivo que el previsto para el común de los créditos". Aunque, como apreciaremos, la última parte de dicha definición no puede aplicarse al Derecho chileno, en que el legislador ha optado por una única consecuencia (degradatoria) en relación con este tipo de créditos.

38 Garrido (n. 29), p. 1659.

${ }^{39}$ Formulación que expresamente ofrece el apartado V de la Exposición de Motivos de la LC española. Sobre el particular, vid. Garrido (n. 29), p. 1659; Montés Penadés (n. 12), p. 50; Sastre Papiol (n. 20), p. 1130; Kalkmann, C., “\$39 InsO”, en Graf-Schliker, M.L. (dir.), InsO Kommentar, RWS, Colonia, 2012, p. 287. En todo caso, y como hemos indicado en otro sitio (Goldenberg Serrano (n. 1), passim), nos parece que difícilmente se puede sostener hoy un principio de igualdad de trato en el contexto concursal, donde se multiplican reglas de discriminación como las previstas, dando cuenta que no es necesario (ni conveniente) que estimemos que el concurso tiene por finalidad la igualdad de los acreedores, lo que no implica un desconocimiento de la regla de proporcionalidad como general. En este sentido, también puede consultarse a De Cicco, O., "Procedure concorsuali e par condijo creditorum: la protezione dei creditori tra parità e ragionevolezza", Rivista di Diritto dell Impresa, No 2, 2011, p. 344 y Migliaccio (n. 34), pp. 45 y 77.

${ }^{40}$ Alonso Ledesma (n. 29), p. 390.

${ }^{41}$ Sebastián Quetglas, R., "La subordinación de los créditos en los grupos de sociedades, en Créditos, garantías y concurso. Estudios jurídicos en homenaje al profesor Ruiz de Velasco, Civitas Thomson Reuters, Cizur Menor, 2010, p. 449. 
cuanto la renuncia resulta siempre del ejercicio de la autonomía privada, envolviendo una manifestación de la voluntad de carácter abdicativo ${ }^{42}$, lo que no parece simple encuadrar la noción de una renuncia ex lege; y porque difícilmente pueda advertirse el rango sobre el que se ejercería dicha renuncia, toda vez que dicho concepto resulta propio de la ordenación de los derechos reales, generalmente, en el contexto de un registro ${ }^{43}$.

Ahora bien, para resolver el punto podría parecer relevante el expediente que se ofrece a partir de los argumentos antes utilizados para la incardinación de los créditos subordinados en la trama que supone la prelación de créditos. Como advierte Alemany Eguidazu, la referencia antes anotada en cuanto a la reconducción de la subordinación a la idea del "antiprivilegio", "no es la panacea para la determinación del régimen jurídico de la subordinación, pues debe rechazarse que la subordinación sea un concepto simétrico perfecto del privilegio o de la preferencia" ${ }^{44}$. Si bien el parangón puede ser aceptado en cuanto regla de graduación del crédito, la identidad no parece admisible si se atiende al sentido propio del privilegio que, carente de definición en nuestro ordenamiento vigente, ha sido conceptualizado como "el derecho que el legislador otorga a un crédito en consideración a la naturaleza de este, y que habilita a su titular para pagarse con preferencia a otros acreedores" 45 .

En primer término, porque difícilmente la subordinación puede configurarse como un derecho del acreedor subordinado, allí donde no ofrece una satisfacción preferente como mecanismo de refuerzo de la tutela de su crédito, sino, lisa y llanamente, una degradación ${ }^{46}$. Se podría advertir que, desde el punto de vista de los acreedores no subordinados, especialmente los valistas, la idea se mantendría constante por cuanto se les concedería una posibilidad de satisfacción de manera prioritaria al crédito legalmente pospuesto. Pero creemos que esta conclusión resulta también errada, porque su mejor posición no resultará de una especial naturaleza de su propio crédito, indistinto para el legislador al tiempo de calificarlo residualmente como valista, sino que se verificará como un efecto reflejo de la posposición del crédito subordinado.

${ }^{42}$ De ahí su calificación como negocio jurídico unilateral, como ejemplifica Díez-Picazo, L., Fundamentos del Derecho civil patrimonial, T, I, Introducción, Teoría del Contrato, Thomson Civitas, Cizur Menor, 2007, p. 93, y, en nuestro ordenamiento, por todos, Vial del Río, V., Teoría general del acto jurídico, Editorial Jurídica de Chile, Santiago, p. 37.

43 Veiga Copo (n. 24), p. 1242 (nota 2.125).

44 Alemany Eguidazu, J., "Subordinación contractual y subordinación concursal" Diario La Ley, No 6.004, Año XXV, 26 de abril de 2004, recurso electrónico.

45 Abeliuk Manasevich (n. 22), p. 1152.

${ }^{46}$ Respecto de la conceptualización de la preferencia como derecho, vid. Garrido (n. 1), p. 37. Especial referencia hacemos a su crítica a la imprecisión de quienes configuran el privilegio como una cualidad del crédito, porque se ofrece un concepto jurídico desconocido por la dogmática jurídica y que no ofrece parámetros ciertos para su construcción (p. 79). De ahí que pueda controvertirse la reconducción efectuada por la doctrina nacional (Bahamóndez Prieto (n. 22), p. 37) y nuestra jurisprudencia (por ejemplo, considerando octavo de la sentencia de la Corte Suprema, de 12 de agosto de 2013, en autos caratulados "Alejandra Silva Aguilera y otros con Miguel Arancibia Silva", rol 1.987-2013, disponible en la base de datos de Legal Publishing bajo el código CL/JUR/2852/2013). 
Luego, si bien la referencia a la naturaleza del crédito puede parecer equívoca, la alusión se refiere principalmente a su calidad o causa ${ }^{47}$, entendida como las "características peculiares de la relación crediticia tutelada" ${ }^{48}$, conforme con la conceptualización dada en el ordenamiento francés y sus orígenes en las reglas romanas ${ }^{49}$, y replicada en ciertas normas patrias hoy derogadas ${ }^{50}$. Y es en este punto donde debemos entender que, salvo en caso de la subordinación de los intereses que se devenguen con posterioridad a la resolución de liquidación (artículo 139 LRLAEP), se produce una distancia evidente. En los demás casos, la "naturaleza del crédito" no es considerada por el legislador para la integración de la tipología de los créditos legalmente pospuestos, reposando en expedientes conductuales [artículos 57.1.c), 264.4 y 292 LRLAEP] o subjetivos y temporales (artículos 63 y 241 LRLAEP), pero advirtiéndose neutros en cuanto al tipo de relación jurídica de la cual emanan ${ }^{51}$.

Otro elemento de análisis se refiere a si de la minusvaloración del crédito puede concluirse la existencia de un juicio de valor que atienda a un criterio estrictamente sancionatorio. O, dicho de otro modo, si la decisión del legislador por subordinar ciertos créditos debe observarse desde la perspectiva única de una pena privada ${ }^{52}$. La cuestión se advierte difusa, particularmente si se atiende al escaso consenso doctrinal respecto de la delimitación técnica de dicho tipo de penas, especialmente allí donde se identifica una tipología tan amplia de supuestos ${ }^{53}$. Sin perjuicio de lo anterior, la categoría podría presentarse como admisible cuando pueda identificarse una violación de un precepto normativo, generando un castigo al actuar ilícito ${ }^{54}$, superando los deslindes de la responsabilidad, y, en el caso, resolviendo por medio de una privación o limitación de derechos 55 .

${ }^{47}$ Troplong, M., Le Droit civil expliqué suivant l'ordre du code. Des priviléges et hypothèques, Vol. I, Sociètè Typographique Belgue, 1844, p. 38.

48 Garrido (n. 1), p. 78.

${ }^{49}$ El artículo 2.095 del Code Civil define el privilegio precisamente como un derecho que la calidad del crédito otorga a un acreedor para ser preferido a otros acreedores, incluso hipotecarios. Definición, en todo caso, que recoge su fuente de L. 32, D. de reb. auct. jud. possid., al señalar que Privilegia non ex tempore aestimatur, sed ex causa, et si ejusdem fuerint tituli, concurrent, licet diversitas temporis in his fuerit.

${ }^{50}$ Así, el artículo $4^{\circ}$ de la Ley de prelación de créditos del 31 de octubre de 1845 se acercaba a la noción de privilegio como aquel que "depende únicamente de la naturaleza del crédito, sin relación a su fecha; i prefiere a todas las hipotecas i escrituras, aun las que sean anteriores a la causa del privilejio"; al tiempo que el artículo $7^{\circ}$ de la Ley de prelación de créditos del 25 de octubre de 1854 le definía como "el derecho de ser pagado con preferencia a cualquiera otra clase de acreedores, en razón de la naturaleza del crédito i sin consideración a su fecha”.

${ }^{51}$ En los mismos términos que Garrido (n. 29), p. 1661 nos indica que, paralelamente a la determinación de la causa del crédito como justificación de los privilegios generales, otro tanto debe efectuarse en la fijación de la causa de la subordinación para la comprensión de cada uno de los supuestos previstos por la legislación.

52 Alemany Eguidazu (n. 44), recurso electrónico.

${ }^{53}$ Moscati, E., "Pena (dir. priv.)", en Enciclopedia del Diritto, T. XXXII, Giuffré, Milán, 1982, p. 780.

${ }^{54}$ Diurni, G., "Pena privata (dir. interm.)", Enciclopedia del Diritto, T. XXXII, Giuffré, Milán, 1982, p. 470 .

55 Alarcón Soto, A., La pena privada, Ediciones Jurídicas Santiago, Santiago, 2005, pp. 43-44. 
La doctrina comparada se ha presentado vacilante acerca de este aspecto ${ }^{56}$, aunque, en gran medida, las conclusiones no pueden ser completamente trasplantadas, ya que los argumentos se han construido en torno al tenor específico de sus normas ${ }^{57}$. En el marco del Derecho nacional, nos parece que no puede ofrecerse una única explicación que justifique la decisión del legislador para la calificación de los créditos como legalmente pospuestos, especialmente si trata de advertirse la finalidad punitiva antes referida. En primer término, en el caso de los intereses devengados con posterioridad a la resolución de liquidación (artículo 139, inciso quinto, LRLAEP), nos parece que la ausencia de un carácter sancionatorio de la posposición es evidente, ya que, por una parte, es aplicable a todos los créditos concursales, sin distinción, y, por la otra, porque no se advierten razones para justificar un reproche, porque ni siquiera se requiere de una conducta por parte de los acreedores. Al parecer, el legislador observa que, en razón del cobro de los intereses, pueden producirse distorsiones al ideal de paridad que envolvería el concurso $^{58}$, de manera que los acreedores que hayan logrado pactar intereses mayores a los corrientes, podrían obtener un mayor cobro que aquellos que no han pactado interés alguno (artículo 139, inciso primero, LRLAEP) ${ }^{59}$.

Luego, en el caso de los créditos legalmente pospuestos en razón de la titularidad de las personas relacionadas al deudor, la cuestión resulta algo más compleja si se observa el automatismo de la solución degradatoria y la ausencia de una referencia a otras elaboraciones dogmáticas de esta clase de reacciones legislativas, que, en el Derecho comparado, parecen sustentarse sobre la idea de un reproche a la infracapitalización, al incumplimiento de los deberes fiduciarios de quienes tienen una participación societaria o administrativa o al abuso de la mayor información que estos poseerían ${ }^{60}$. Al contra-

\footnotetext{
${ }^{56}$ Veiga Copo (n. 24), p. 1244.
}

${ }^{57}$ Por ejemplo, la tesis del carácter indemnizatorio prima en el Derecho norteamericano, al tiempo que el artículo 510 USC 11 admite una subordinación total o parcial del crédito, pero siempre hasta la extensión del daño, porque "los tribunales actúan como tribunales de equidad para reparar un mal específico, pero no para establecer un castigo" Chaitman, H.D., "The equitable subordination of bank claims", The Business Lawyer, $\mathrm{N}^{\circ} 39,1983-1984$, p. 1564 (traducción del autor). En España, por su parte, aboga por el carácter sancionatorio Sebastián Quetglas (n. 41), pp. 443 y 446-448, al tiempo que Garrido (n. 29), p. 1666 distingue según el tipo de subordinación, confiriendo, por ejemplo, un carácter indemnizatorio a la subordinación de créditos de las personas relacionadas (artículo 92.5 LC), y sancionatorio al crédito del tercero de mala fe, vencido en el ejercicio de las acciones de reintegración (artículo 95.6 LC).

${ }^{58}$ Y, como indicó la Superintendenta de Quiebras, Josefina Montenegro, se resolvería como un efecto adicional de la fijación irrevocable de los derechos de los acreedores al día de la dictación de la correspondiente resolución de liquidación (Historia de la Ley, Informe de la Comisión de Constitución, Legislación y Justicia de la Cámara de Diputados, p. 2115).

59 Si bien el artículo 139 LRLAEP propone la posposición de los intereses que se devenguen con posterioridad a la dictación de la resolución de liquidación, es esencial observar que esta medida no resulta especialmente novedosa en nuestro ordenamiento. Con una diferente justificación técnica, basada en la suspensión del devengo de intereses, la Ley 4.558, de 1929, conseguía similares efectos degradatorios (Puga Vial, J.E., Derecho concursal. Del procedimiento concursal de liquidación. Ley 20.720, Editorial Jurídica de Chile, Santiago, 2014, pp. 631-632).

${ }^{60}$ En este sentido, vid. la explicación dispuesta en la sección 48 del Capítulo V de la Guía Legislativa de la CNUDMI sobre el régimen de la insolvencia (sección 48 del Capítulo V). 
rio, en el contexto de la discusión legislativa, la redacción inicial de la norma pareció sustentarse en una práctica habitual en el marco de los convenios judiciales, cuestión que hubiese implicado una tipificación de una solución disponible en el marco de las diversas justificaciones a la subordinación voluntaria de créditos ${ }^{61}$. Por ello, al parecer, la real motivación que se tuvo en consideración para la mantención de la norma prevista en el artículo 63 LRLAEP se encontraba en evitar "el riesgo de la alteración del pasivo mediante la creación de créditos relacionados no justificados" 62 . Sobre la base de este criterio se avanzó hasta alcanzar la redacción final de la norma, particularmente a partir de la intervención del senador Andrés Zaldívar, quien propuso distinguir entre "créditos de la cuenta corriente y los créditos documentarios", ya que, a su juicio, los primeros "podían ser objeto de manipulación, mientras que los segundos están dotados de una mayor seriedad" 63 , llevando a que se agregara a la norma un requisito para la operatividad de la subordinación de los créditos de las personas relacionadas, referido a la inexistencia de documentación dentro de un periodo de noventa días antes del inicio del procedimiento concursal de reorganización ${ }^{64}$.

A nuestro juicio, en este tipo tampoco estamos propiamente frente a una sanción, a menos que se construya sobre la ambigua idea de la infracción a un supuesto deber que se impondría a las personas relacionadas y al deudor consistente en la documentación de sus obligaciones, sino sobre la base de una aparente sospecha de inexistencia del crédito, de lo que da cuenta la discusión legislativa antes reseñada ${ }^{65}$. Sospecha que parece resolverse de manera tardía si se considera que, a efectos que pueda aplicarse la regla de graduación, será necesario que el crédito se encuentre incorporado en la nómina de créditos reconocidos, habiendo superado las instancias de objeción e impugnación que articulan los artículos 70 y siguientes LRLAEP en materia de reorganización, y artículos

${ }^{61}$ En este sentido, Contador Rosales, N. y Palacios Vergara, C., Procedimientos concursales, Thomson Reuters La Ley, Santiago, 2015, p. 83. No obstante, estimamos que la posposición legal requiere de la identificación de un elemento, sea del mismo crédito, sea del comportamiento del acreedor, que amerite la reacción legislativa, como base de la axiología propia de las reglas de graduación sobre los pilares de la justicia distributiva, volviendo nuevamente a las distancias que sobre el punto se producen entre la subordinación voluntaria e involuntaria.

62 Una de las justificaciones dadas al efecto por la señora Alejandra Anguita, Jefa del Departamento Jurídico de la Superintendencia de Quiebras. Punto que fue posteriormente tomado por el senador Espina a efectos de indicar que "el riesgo práctico es que se constituyan falsamente acreencias y que ellas, relacionadas con la empresa, se paguen y recuperen dineros indebidamente" (Historia de la Ley, Segundo Informe de las Comisiones Unidas, pp. 667 y 670).

${ }^{63}$ Historia de la Ley, Segundo Informe de las Comisiones Unidas, p. 669.

${ }^{64}$ Créditos documentados que, según expresó el senador Tuma, son "para la historia de la ley", los que se encuentran emitidos y están registrados por el deudor" (Historia de la Ley, Segundo Informe de las Comisiones Unidas, p. 674), y, que conforme a Contador Rosales y Palacios Vergara (n. 61), p. 83, se refieren a un crédito que "debe constar en algún título válido donde se exprese inequívocamente el monto y características del crédito”.

${ }^{65}$ Así también Contador Rosales y Palacios Vergara (n. 61), p. 83, al observar que "existen muchos casos en que los créditos provenientes de personas relacionadas tienen una existencia clara y no debieran ser discriminados", justificando el establecimiento de la documentación en los noventa días previos al inicio del procedimiento concursal de reorganización. 
170 y siguientes LRLAEP en materia de liquidación ${ }^{66}$. Así, es posible preguntarse si estamos frente a un supuesto que realmente requiere ser tratado en los términos establecidos en la norma, e, incluso, si el automatismo con que ella se presenta sobre una base objetiva, casi a modo de presunción de derecho de la existencia de alguna suerte de fraude ${ }^{67}$, se justifica aun cuando se ha dado lugar a la comprobación de su existencia y licitud en sede de reconocimiento del crédito ${ }^{68}$.

Finalmente, frente a los supuestos de infracción a la protección financiera concursal [artículos 57.1,c) y 264.4 LRLAEP] y a la verificación del crédito del tercero vencido en la acción revocatoria (artículo 292 LRLAEP), estimamos que sí puede advertirse una justificación penalizadora. En el primero, porque el acreedor habrá vulnerado un efecto propio de la resolución de reorganización o de la resolución de admisibilidad, según el procedimiento en que tenga lugar, desatendiendo la pretensión del legislador de conservar la vigencia de los contratos y los plazos a los que se encuentran sujetos los créditos, de manera de no provocar un deterioro en las expectativas de reestructuración y en el equilibrado desarrollo de la negociación ${ }^{69}$; y, en el segundo, porque resultará que, para

66 Por ello, bien puede traerse en mente la crítica esbozada por Blasco Gascó (n. 36), p. 327, en la órbita del Derecho español, en cuanto se "trata aquí de una postergación o subordinación basada en una oculta presunción de fraude, de manera extravagante y con poco sentido, pues si se presume el fraude o la falsedad del crédito, los mecanismos jurídicos deben ser otros que no la postergación en el cobro, pues parece que se quiere decir que hay fraude pero no mucho o que se presume el fraude pero poco o no lo bastante para declarar la nulidad del contrato".

${ }^{67} \mathrm{O}$, como indicó el senador Espina, mediante un "criterio general y objetivo" (Historia de la Ley, Segundo Informe de las Comisiones Unidas, p. 674), de ello advertimos que no es necesario acreditar el fraude, ni se admite que los acreedores personas relacionadas puedan liberarse de la posposición en ausencia del mismo.

68 Este punto ha quedado en evidencia en el procedimiento concursal de reorganización de la Cooperativa Agrícola Lechera Bío Bío Limitada. Al efecto, considerando la verificación de ciertos créditos por parte de personas relacionadas a la empresa deudora, los objetantes (luego, impugnantes) expusieron, en primer término, que ellos derivarían de ciertos actos civiles (novaciones, reconocimiento de deuda, reserva de garantías y compensación), con el fin de aumentar su pasivo, favoreciendo indebidamente a los acreedores, ya que el primitivo deudor se encontraba sometido a un procedimiento de liquidación concursal; y, en subsidio, solicitando la calificación de dichos acreedores como personas relacionadas al deudor, para efectos de la posposición en el pago de los créditos por la ausencia de documentación en los noventa días precedentes al inicio del procedimiento. Al efecto, el tribunal resolvió todas dichas impugnaciones sobre la base de la falta de acreditación de los antecedentes justificativos de dichos créditos, impidiendo su inclusión en la nómina de créditos reconocidos, y sin necesidad de resolver la posposición de créditos originalmente solicitada (sentencias del $1^{\circ}$ Juzgado de Letras de Los Ángeles, de 10 de marzo de 2015, en autos caratulados "Cooperativa Agrícola Lechera Bío Bío Limitada”, rol 6-366-2014, disponibles en www.boletinconcursal.cl [consultado el día 16 de marzo de 2015]).

${ }^{69}$ A este respecto, como señala Puga Vial, J.E., Derecho concursal. El acuerdo de reorganización, Editorial Jurídica de Chile, Santiago, 2014, p. 245, "la sanción no surge por el hecho de que exista una cláusula en tal sentido, que además es ineficaz, sino por el hecho de intentar ponerle término unilateralmente o intentar ejecutar el acto". Ineficacia de la cláusula que es reconducida por Contador Rosales y Palacios Vergara (n. 61), p. 67 , al hecho que deba entenderse por no escrita. Por ello, la posposición se presenta como una sanción eventual basada en un comportamiento desplegado por el contratante que, a la vez, es un acreedor dinerario de la empresa deudora, y que termina por desfavorecer sus posibilidades de cobro mediante la técnica de la posposición legal. 
la operatividad de la regla habrá sido necesaria la acreditación de los requisitos establecidos para la revocación subjetiva (artículo 288 LRLAEP), uno de carácter objetivo, como es la separación del negocio jurídico de las condiciones habituales que imperan en el mercado, o la desatención al ideal de igualdad de trato, y uno de carácter subjetivo, referido al conocimiento del mal estado de los negocios por parte del deudor ${ }^{70}$. Ambos elementos configurarán un reproche a la conducta y justificarán, no solo la revocación del acto en cuestión, sino también el carácter pospuesto del acreedor al intentar recobrar su crédito en la masa concursal ${ }^{71}$.

Ahora bien, lo anterior nos permite anticipar que no creemos que pueda ofrecerse una única explicación de la naturaleza jurídica de la subordinación legal, si no es acaso la de constituirse como una regla de graduación. Ello implica que el deterioro de las posibilidades de cobro de los titulares de esta clase de créditos no es sino el efecto de una decisión normativa, que emplea la técnica de la degradación por un número de expedientes diversos, pero que se deben entender incardinados en la finalidad satisfactoria del concurso. De este modo, en cada uno de los tipos previstos por la LRLAEP deberán buscarse sus particularidades, a objeto de que, salvo en lo que se refiere al citado efecto degradatorio, pueda integrarse a cabalidad su particular régimen jurídico, siempre sobre la base de mejorar las posibilidades de cobro de los acreedores no subordinados.

\section{LA SUBORDINACIÓN LEGAL EN EL ÁMBITO CONCURSAL}

\section{Función y operatividad de la regla de subordinación legal en el contexto concursal}

Desde la perspectiva de la conclusión preliminar con la que hemos terminado el acápite precedente, creemos necesario recalcar la función esencial que cumple la subordinación legal de créditos como técnica incorporada en el ámbito concursal. Al efecto, la doctrina extranjera, ante similar irrupción de la figura en la modernización de sus regímenes jurídicos, ha evidenciado objetivos eminentemente prácticos, como son el fortalecimiento de la posición económica y la "protección de los intereses de la masa pasiva ordinaria, pues elimina de la concurrencia a una serie de acreedores, o lo que permite ampliar el patrimonio concursal disponible para ellos" 72 .

${ }^{70}$ El carácter sancionatorio que, creemos, fundamenta la norma permite eludir las críticas esbozadas por Puga Vial, J.E. (n. 59), p. 493, que califica esta decisión legislativa como una "burla" o un "verdadero abuso".

${ }^{71}$ De este modo se expresó la Superintendenta de Quiebras, Josefina Montenegro, a efectos de introducir esta regla de posposición allí donde el texto del proyecto originalmente no contemplaba, señalando que "de lo contrario, se produciría un beneficio para dicho contratante, quien podría recuperar lo pagado, a pesar de haber participado en la celebración de un acto revocable" (Historia de la Ley, Informe de la Comisión de Constitución, Legislación y Justicia de la Cámara de Diputados, p. 2220).

${ }^{72}$ Ferré Falcón (n. 5), p. 693. En el ámbito del Derecho chileno, Ugarte Godoy (n. 10), p. 387 había advertido que la subordinación (aunque se refiere a la posposición voluntaria, previo a la reforma de la Ley 20.190) implicaba una suerte de preferencia para los acreedores de la quinta clase, creando una especie de sexta clase, lo que solo podría haber sido establecido por el legislador. 
Sin embargo, Blasco Gascó, advirtiendo que se trata de una categoría novedosa, revirtiendo en una mejora de la posición de los créditos ordinarios, concluye que "posiblemente sea una mejora pírrica por la cantidad y voracidad de los créditos que gozan de privilegios especiales y de privilegios generales" ${ }^{\prime 73}$, materia que estimamos replicable en el Derecho nacional si se observan los índices de recuperación de créditos existentes en nuestros procedimientos concursales ${ }^{74}$. Por ello, este tipo de soluciones no puede observarse aisladamente en el contexto concursal, sino en concordancia con la finalidad propia del concurso ${ }^{75}$. Interés que, a nuestro juicio, y, al menos en nuestro ordenamiento jurídico, debe reconducirse a la protección del crédito por medio de la maximización de las posibilidades de $\operatorname{cobro}^{76}$, y que justifica, por ejemplo, que el crédito de la persona relacionada al deudor, aun cuando cumpla con los requisitos previstos en el artículo 63 LRLAEP, se libere de los drásticos efectos de la subordinación e, incluso, reciba la protección concedida a los créditos privilegiados conforme al artículo 2472, número 4 CC, en los casos en que concedan créditos a la empresa deudora (artículo 63, en relación con el artículo 74 LRLAEP $)^{77}$. Lo anterior, si comprendemos que la dotación de recursos, en el arco temporal que supone la protección financiera concursal, puede resultar en un elemento central para la efectiva reorganización de la empresa ${ }^{78}$, especialmente ahí donde la obtención de recursos frescos sea considerada indispensable por parte de la mayoría de los acreedores para la fórmula de rescate.

Por su parte, respecto de la operatividad de las reglas de subordinación legal, el ordenamiento chileno ofrece dos posibilidades. La regla general estará dada por una subordinación aparentemente automática, en el sentido en que no se requerirá una especial declaración por parte del tribunal que pondere los hechos generadores de la posposición conforme a su tipificación legal. Ello ocurre especialmente en el caso de los intereses que se devenguen con posterioridad a la resolución de liquidación, pero también debería observarse en los créditos de las personas relacionadas cuyos créditos cumplan con los requisitos (temporales y de ausencia de documentación) previstos en los artículos 63 y 241 LRLAEP $^{79}$. Respecto de los créditos resultantes de la revocación

${ }^{73}$ Blasco Gascó (n. 36), p. 321.

${ }^{74} \mathrm{Al}$ efecto, basta revisar el informe de Doing Business 2015, del Banco Mundial, que señala que nuestro sistema concursal ofrece una tasa de recuperación promedio de 30 centavos por dólar (http://espanol. doingbusiness.org/data/exploreeconomies/chile/\#resolving-insolvency [consultada el 13 de marzo de 2015]).

${ }^{75}$ Bermejo Gutiérrez (n. 11), p. 436.

76 Goldenberg Serrano, J.L. "Bases para la privatización del Derecho concursal”, Revista Chilena de Derecho Privado, No 20,2013 , p. 9-49.

${ }^{77}$ Norma que se recoge en el Derecho comparado, especialmente en el marco del Derecho colombiano (artículo 69, párrafo $3^{\circ}$ de la Ley 1.116, de insolvencia empresarial), fuente de inspiración del nuevo procedimiento concursal de reorganización.

78 Goldenberg Serrano, J.L., "Justificación y fórmulas de protección al financiamiento de rescate”, Revista de Derecho Privado (Universidad del Externado, Colombia), No 26, 2014, pp. 351-384.

${ }^{79}$ Excepción debe ser hecha al caso de posposición prevista en la parte final del artículo 63 LRLAEP, que admite que la junta de acreedores subordine el pago de las personas relacionadas, aun si estuvieren documentadas dentro del plazo de 90 días, previo informe fundado del veedor. Se trata este de un supuesto que parece acercarse a la subordinación voluntaria, ya que no proviene directamente de una decisión 
concursal, si bien el artículo 292 LRLAEP dispone que se trata de un efecto que debe ser establecido en la resolución que ha acogido la demanda, ello no implica una revisión por parte del tribunal competente del cumplimiento o no de los supuestos de la posposición crediticia, sino únicamente de los elementos a considerar para la operatoria de las acciones revocatorias concursales. En otras palabras, concedida la revocación del acto o contrato, la subordinación del crédito operará de manera automática en caso que el tercero haya optado por aceptar la revocación, decidiéndose por la verificación del crédito en el procedimiento concursal respectivo, y no por su consolidación mediante el pago del remanente para completar el precio de mercado (artículo 292, inciso segundo LRLAEP).

Sin embargo, en el caso de la infracción a la protección financiera concursal que opera a partir de la publicación de la resolución de reorganización en el Boletín Concursal, la subordinación del crédito deberá ser declarada judicialmente, en uno de los pocos incidentes que la LRLAEP admite en el curso de un procedimiento concursal Lartículos 5 y 57.1.c) LRLAEP]. La falta de automaticidad en este caso se justifica en la necesaria constatación del supuesto de hecho que conllevará la posposición del crédito, como es el caso de haber mediado una actividad consistente en la contravención a la prohibición de terminación unilateral del contrato, exigencia anticipada de los créditos o ejecución de garantías, invocando como causal el inicio de un procedimiento concursal de reorganización. La verificación de esta circunstancia, por tanto, no queda en manos del veedor ni de la junta de acreedores, quienes no tienen competencia para decidir acerca del punto, sino del tribunal que debe atender a la efectiva obstrucción del proceso de negociación por parte del titular del crédito por medio de alguna de las circunstancias previstas en el procedimiento ${ }^{80}$. En este sentido, creemos que la operatividad de la norma tampoco se construye sobre elementos subjetivos, sino que se resuelve nuevamente sobre la existencia de una actividad en particular, que debe ser constatada ante tribunales ${ }^{81}$.

legislativa, sino de la decisión de la junta de acreedores, pero se alejará de aquella porque no contará con el consentimiento de los acreedores subordinados, que, tratándose de personas relacionadas, carecerán de derecho a voto (artículo 79 LRLAEP). La discusión legislativa respecto de esta norma no es clara. Al efecto, inicialmente se pretendía ofrecer una excepción a la posposición legal de los créditos de las personas relacionadas, previo informe favorable por parte del veedor, sujeto a la aprobación de la junta de acreedores (Historia de la Ley, Segundo informe de las Comisiones Unidas, p. 674). Sin embargo, la disposición que resultó finalmente aprobada expresa exactamente lo contrario: permite que los créditos que no cumplen con las condiciones para la operatividad de la regla degradatoria (esto es, la documentación en el arco temporal previsto por la norma) sean igualmente pospuestos.

${ }^{80}$ En el mismo sentido se presenta en España la subordinación legal prevista en el artículo 92.7 LC, en el sentido que el juez del concurso debe constatar, previo informe de la administración concursal, que el acreedor obstaculiza de forma reiterada el cumplimiento del contrato en perjuicio del interés del concurso. Por su parte, en el ordenamiento colombiano, de donde se nutre la disposición en comento, no se indica expresamente la necesidad de declaración judicial de la posposición, sino que, conforme al artículo 16 de la Ley 1.116, solo se dispone que de verificarse la ocurrencia de la ineficacia de la estipulación contractual que tenga por objeto impedir u obstaculizar directa o indirectamente el inicio de un proceso de reorganización y, de haberse intentado hacer efectiva la cláusula el acreedor, resultará la postergación legal del crédito.

${ }^{81}$ Es admisible observar, sin embargo, que la norma ofrece ciertas distancias con el efecto previsto en el artículo 264.4 LRLAEP en el marco de los efectos de la resolución de admisibilidad dictada en un 


\section{Características generales de los créditos legalmente pospuestos:}

Si bien ya hemos anticipado la diversidad de justificaciones para la reacción degradatoria ofrecida por nuestro renovado sistema concursal, como también a las dificultades que implica la elaboración de una disciplina fundada en una idéntica naturaleza, creemos que no puede descartarse el esfuerzo de encontrar notas comunes para integrar el régimen jurídico general de esta clase de créditos, los que destacamos a continuación.

\section{a. Créditos concursales}

En primer lugar se trata de créditos concursales, vale decir, integran la masa pasiva del concurso. La subordinación legal no priva al crédito de la dimensión básica que surge de su naturaleza obligatoria ${ }^{82}$, emanada de la regla de la responsabilidad patrimonial universal, que constituye, como indica Migliaccio, un prius de toda otra consideración de paridad o disparidad de tratamiento, funcionando únicamente al interior del conjunto de acreedores como una articulación que se hará efectiva al tiempo de la distribución ${ }^{83}$.

Para tales efectos deberá tratarse de créditos que han sido objeto de reconocimiento en el procedimiento concursal respectivo por medio de los diversos expedientes que contiene la LRLAEP, o, al menos, créditos a los cuales los resultados del concurso le son expresamente oponibles, a pesar de no haber efectuado actuación alguna (por ejemplo, por el hecho de ser considerados en la masa pasiva del deudor por constar en el informe del auditor independiente que debe presentarse al inicio del procedimiento concursal de reorganización, conforme a los artículos 55 y 70 LRLAEP). Lo anterior se expresa de manera bastante clara en el artículo 292 LRLAEP, al tiempo que se permite al tercero cuyo acto ha sido revocado, verificar el crédito en el procedimiento concursal respectivo, aunque sujeto a la posposición que la ley ordena, y que denota el principio fundamental, previsto tanto en el Derecho patrio como comparado, de dotar al concurso de herramientas para la correcta identificación de la totalidad del pasivo del deudor ${ }^{84}$.

procedimiento concursal de renegociación. Por una parte, el catálogo de conductas que pueden dar lugar a la posposición legal del crédito se presenta de manera abierta y no taxativa (cualquier acción), haciendo referencia a sus resultados, como son la terminación del contrato o la exigencia anticipada de los créditos, lo que, a nuestro juicio, incorpora una tutela bastante más completa para la negociación que aquella que ofrece el artículo 57.1.c) LRLAEP en el contexto de la reorganización, pero puede ocasionar un difícil debate para verificar la constatación del hecho que amerita la reacción subordinatoria. Lo anterior se suma a que la norma no indica una regla procesal para la acreditación de las conductas que pueden dar lugar a la posposición del crédito, lo que se relaciona con el hecho que la Superintendencia de Insolvencia y Reemprendimiento no tiene asignadas facultades jurisdiccionales, dado que se trata de un procedimiento de tipo administrativo en que esta tiene funciones de facilitación de los acuerdos.

${ }^{82}$ O, como señala Sebastián Quetglas (n. 41), p. 449, la subordinación no desnaturaliza el créditos, especialmente en aquellos casos en los que se ofrece como una respuesta del ordenamiento concursal para la adecuada conformación de los recursos propios de la empresa, sin llegar, en consecuencia, a su recalificación como aportes societarios a efectos de integrar su régimen jurídico.

${ }^{83}$ Migliaccio (n. 34), pp. 69 y 70.

${ }^{84}$ Locoratolo, S., Postergazione dei crediti e fallimento, Giuffrè Editore, Milán, 2010, p. 96. 
De la calificación de crédito concursal se derivan también algunas consecuencias. En primer término, poseen iguales derechos que el resto de los acreedores, según la clase o categoría que les corresponda, con excepción de su posición en la escala de prelación en atención a la aplicación de la regla de degradación del crédito ${ }^{85}$. Esta idea les permitirá participar en las resultas del procedimiento concursal, aunque probablemente ello no ocurrirá en la mayor parte de los casos, debido a que el ordenamiento no ha tomado la opción de impedir su participación en el concurso, como ocurría en la $\$ 63$ de la Konkursordnung alemana de $1898^{86}$. Al respecto, uno de los principales avances en el tratamiento de esta clase de créditos en el referido ordenamiento se refiere precisamente a este hecho, toda vez que la doctrina alemana ha convenido en que, de quedar un remanente, este debe ser igualmente distribuido entre los acreedores, y no volver directamente a manos del deudor, como ocurría en el sistema anterior, porque este resultado aparecía injustificado ${ }^{87}$.

${ }^{85}$ Conservándose, en lo demás, el régimen jurídico dispuesto para la generalidad de los créditos concursales, los titulares de los créditos subordinados podrán igualmente participar en los procesos de nominación de los veedores y liquidadores (artículos 22 y 37 LRLAEP); se sujetarán a las reglas de determinación del pasivo (artículos 70, 71 y 170 a 179 LRLAEP); se integrarán a la respectiva clase de acreedores en los acuerdos de reorganización (artículo 61 LRLAEP); gozarán de derecho a voto (artículos 79, 189 a 191, y 265 LRLAEP); podrán formar parte de las comisiones de acreedores (artículos 69 y 202 LRLAEP); y se le asignarán iguales facultades impugnatorias de los acuerdos, como también para hacer valer nulidades o denunciar incumplimientos (artículos 85, 97 y 98 LRLAEP), entre otras. La excepción está dada para las personas relacionadas al deudor, pero, en este caso, la normativa concursal no ha asociado la privación de derechos al carácter subordinado del crédito, sino especialmente a su carácter de acreedores complacientes, casi a modo de una presunción de derecho de conflicto de intereses que les impediría razonar en torno a los parámetros de eficiencia que pretende el concurso. De este modo, el carácter de personas relacionadas por parte del titular, conforme al listado previsto en el artículo 2.26 LRLAEP, ocasionará, adicionalmente, la pérdida de derechos políticos para participar en los procesos de nominación de veedores y liquidadores (artículos 37 y 55 LRLAEP); aceptar una prórroga de la protección financiera concursal (artículo 58 LRLAEP); votar en la junta de acreedores convocada para el conocimiento y deliberación de las propuestas de acuerdo de reorganización presentadas por el deudor, como también en las juntas que puedan celebrarse con posterioridad a la aprobación de dichos acuerdos, y en las juntas y audiencias que tengan lugar en los procedimientos concursales de liquidación y renegociación de deudas, según el caso (artículos 79, 83, 191, 258, 265, 266 y 267 LRLAEP); y suscribir acuerdos de reorganización extrajudicial (artículo 109 LRLAEP). Por su parte, tampoco podrán deducir como gastos necesarios para la producción de la renta, las cantidades que correspondan a la condonación o remisión de deudas, intereses, reajustes u otras cantidades que se hayan devengado en su favor (artículo 93 LRLAEP) ni obtendrán el régimen tributario especial en materia de impuesto al valor agregado para imputar el tributo pagado por facturas cuyos créditos han sido objeto de un acuerdo de reorganización (artículo 27 ter del decreto ley $\mathrm{N}^{\circ} 825$, de 1974); se ampliará a dos años el periodo de sospecha en el ejercicio de las acciones revocatorias objetivas (artículos 287 y 290 LRLAEP); y no podrán obtener recompensas en razón del ejercicio de las acciones revocatorias concursales (artículo 293 LRLAEP).

${ }^{86}$ Bornemann, A., "§ 39 InsO”, Wimmer, K. (dir.), Frankfurter Kommentar zur Insolvenzordnung, Luchterhand Verlag, Colonia, 2013, p. 621. Aunque, como aclaran Schmidt y Herchen (n. 36), pp. 410-411, en tal caso no se hacía referencia a una categoría de créditos subordinados, sino simplemente a créditos que no podían participar en el procedimiento. Esta posibilidad, alternativa a la subordinación, es observada en la novena sección del Capítulo V de la Guía Legislativa de la CNUDMI sobre el régimen de la insolvencia.

87 Por todos, Eickmann, D., “\$39 InsO”, en Heidelberger Kommentar Insolvenzordnung, C.F. Müller, Hamburgo, 2011, p. 433. 
Por su parte, su calificación como créditos concursales también supone que no se tratará de créditos que nazcan con posterioridad a la apertura del procedimiento por medio de la dictación de la correspondiente resolución de reorganización, liquidación o admisibilidad, porque serán estos créditos contra la masa y se sujetarán a sus propios términos, conforme a las reglas generales. Al efecto, en todos los casos, la alusión de las normas hacen presente que debe tratarse de créditos que tienen causa con anterioridad al inicio del procedimiento, lo que tiene toda lógica, porque si no fuere de este modo, difícilmente el acreedor optaría por conceder créditos al deudor sujeto a un procedimiento concursal si existiese un riesgo de no poder cobrar. En este sentido, el crédito legalmente pospuesto solo podrá ser aquel que, en defecto de la norma de degradación, hubiese calificado como valista, hipotecario o privilegiado, conforme a la calificación que se ofrece en el Título XLI del Libro IV del Código Civil o en otras normas especiales.

\section{b. Crédito debilitado en el respectivo procedimiento concursal}

En segundo lugar, debemos constatar que se trata de un derecho minusvalorado por parte del ordenamiento concursal ${ }^{88}$. Esta idea ha sido reconducida a la categoría de los "derechos debilitados", que, como señala Cannada-Bartoli, se refiere a ciertos derechos subjetivos con una menor eficacia, una vez que se ha producido el hecho productivo del debilitamiento ${ }^{89}$. Si bien la aproximación a los "derechos debilitados" es más bien propia del Derecho administrativo, especialmente para explicar el debilitamiento de la propiedad ante la expropiación, la explicación no se aleja del contexto de la órbita del derecho privado. De tal suerte, el mismo autor nos indica que el referido debilitamiento puede identificarse como la cara opuesta del fortalecimiento de determinados derechos subjetivos, utilizando ejemplarmente el reforzamiento del derecho de crédito por efecto de la constitución de una garantía real ${ }^{90}$. Por ello, un derecho debilitado no implica su extinción, sino un menor poder que el que usualmente le corresponde, especialmente cuando logra identificarse un interés que resulta superior al individual ${ }^{91}$.

En el Derecho español, la calificación de un crédito como subordinado comporta siempre una merma en los derechos que, en otro caso, corresponderían al acreedor, los que se extienden bastante más allá de la posposición en el pago de los créditos, en particular, por la pérdida del derecho a voto (artículo $112 \mathrm{LC})^{92}$. De tal suerte, en el

${ }^{88}$ Veiga Copo (n. 24), p. 1238.

${ }^{89}$ Cannada-Bartoli, E. “Affievolimento”, en Enciclopedia del Diritto, Tomo I, Giuffrè, Italia, 1958, pp. 670-671.

${ }^{90}$ Cannada-Bartoli (n. 89), p. 670.

${ }^{91}$ Como se indica en la sección 56 del Capítulo V de la Guía Legislativa de la CNUDMI relativo al régimen de la insolvencia, "La subordinación consiste en redistribuir el orden de prelación de los acreedores y no afecta la validez ni la legalidad del crédito. Aun cuando sea válido y ejecutable, un crédito subordinado podrá perder, en virtud de un acuerdo o de una declaración judicial, el grado de prelación que le correspondería según el plan de distribución y ser reembolsado después de otro que, en principio, tenía un grado de prelación inferior".

${ }^{92}$ Valpuesta Gastaminza (n. 12), p. 731. 
ordenamiento español, " $[\mathrm{L}] \mathrm{j}$ subordinación del crédito no solo supone que se posterga su satisfacción a la de los créditos ordinarios sino que su titular no interviene en la decisión acerca del modo en que va a satisfacerse. No cabe duda de que así se realza el valor de la voluntad de los acreedores ordinarios, una vez, sobre todo, que su grupo se ha depurado con la conformación de la categoría de los créditos subordinados"93. En el ordenamiento alemán, la solución se presenta más extrema y, sobre la base de la eficiencia y celeridad del procedimiento, los acreedores subordinados no participarán en el concurso, a menos que, conforme a la $\$ 174.3$ InsO, sean citados por el tribunal para estos efectos, ahí donde este estime que existe alguna posibilidad de satisfacción ${ }^{94}$. Lo anterior implica que los créditos, si bien pueden llegar a participar en las resultas del concurso, solo lo harán para efectos del pago, pero en caso alguno integrarán los órganos deliberativos que integran el procedimiento.

Sin embargo, ajena a los expedientes extranjeros, la LRLAEP solo ha optado por un debilitamiento del crédito en el ámbito de su prelación, sin asociar a ello una merma en sus derechos políticos, ni a su posibilidad de intervenir en el concurso en otras esferas, tales como la demanda de un procedimiento de liquidación forzosa (artículo 117 LRLAEP), la objeción e impugnación de créditos (artículos 70, 71, 174 y 175 LRLAEP) y acuerdos (artículo 85 LRLAEP), la posibilidad de integrar comisiones de acreedores (artículos 69 y 202 LRLAEP), entre muchos otros. Pero el principal punto de discordia se encontrará precisamente en el ejercicio del derecho a voto, porque, desde el criterio de la racionalidad económica, podría vaticinarse que el acreedor titular del crédito pospuesto normalmente atenderá a una fórmula reorganizativa, aun si se considera la inviabilidad de la empresa, debido a que la respuesta liquidatoria probablemente conllevará su insatisfacción (considerando, especialmente, el efecto extintivo de los saldos insolutos producto de la dictación de la resolución de término, según el artículo 255 LRLAEP). Así también, probablemente pretenderá la continuidad de las actividades económicas del deudor, incluso en aquellos casos en los que esta no tiene mayor coherencia económica, en atención a la creencia que por medio de ella recuperará una porción del crédito. En razón de lo anterior, acudiendo a la residual owner doctrine ${ }^{95}$, Vattermoli señala que la concesión del derecho a voto al acreedor subordinado representa un factor de grave ineficiencia al procedimiento, que es oportuno eliminar ${ }^{96}$.

Por su parte, resultará que los hechos productivos de la degradación del crédito encuentran un reflejo únicamente en el contexto de alguno de los procedimientos

${ }^{93}$ De la Cuesta Rute, J.M., El convenio concursal. Comentarios a los artículos 98 a 141 de la Ley concursal, Thomson Aranzadi, Cizur Menor, 2004, p. 154.

${ }^{94}$ Kalkmann (n. 39), p. 288.

${ }^{95}$ Se trata esta de una forma de comprender la distribución de poderes al interior del concurso. Pretende justificar que los derechos políticos solo deben corresponder a los acreedores que estén realmente expuestos a riesgo, dependiente de la posibilidad de obtener o no algún nivel de pago, particularmente, una vez satisfechos los acreedores superiores. El problema de la teoría reside en la difícil tarea de determinar el valor de la empresa a efectos de identificar al residual owner (Baird, D. y Jackson, T.H., "Bargaining after the fall and the contours of the absolute priority rule", University of Chicago Law Review, No 55, 1988, pp. 738-789).

96 Vattermoli (n. 5), p. 422. 
concursales previstos en la LRLAEP. Los créditos legalmente pospuestos, por tanto, no tienen operatividad fuera de aquellos, ni en la regulación general del cumplimiento de las obligaciones (ya que se trata de una regla de graduación que solo tiene sentido en el marco de un conflicto entre acreedores ante la evidencia de un patrimonio insuficiente), ni por medio del ejercicio de tercerías de prelación en la órbita del juicio ejecutivo. Lo anterior puede ser comprobado por medio de dos expedientes. Primero, porque no se ha modificado la regla del artículo 2469 CC, que solo reconoce excepciones positivas a la regla de proporcionalidad, al tiempo que la subordinación voluntaria aparece como la única excepción negativa, con pretensión de aplicación general, en el campo de la regulación de los créditos valistas (artículo 2489 CC). Segundo, porque los supuestos de la posposición legal de créditos se relacionan, cada cual, con la dictación de una resolución o el inicio de un procedimiento concursal previsto en la LRLAEP 97.

Lo anterior se justifica porque los hechos que desencadenan la subordinación se encuentran orientados por las diversas finalidades que imperan en la lógica concursal. Así, además de la pretensión genérica de eficiencia que ya hemos apuntado, cada uno de los casos debe satisfacer esta idea a efectos de no aparecer como una herramienta exótica en el marco de los procedimientos concursales, ni verse expuesta a un juicio de discriminación arbitraria. Al efecto, sea para fortalecer el proceso de negociación [artículo 57.1.c) y 264.4 LRLAEP], sea para equilibrar la posición de los acreedores, allí donde se han fijado irrevocablemente sus derechos (artículo 139 LRLAEP) o sea para el aumento del activo disponible para el reparto (artículo 292 LRLAEP), aparece una razón específica que bien calza con dichos parámetros. El supuesto más dudoso, nuevamente, se sitúa en el caso de los créditos de las personas relacionadas (artículos 63 y 241 LRLAEP), a menos que este se justifique en el ideal genérico de eficiencia del concurso y en el establecimiento de un régimen bastante más draconiano respecto de los demás acreedores, por medio de un ostensible debilitamiento de sus derechos económicos y políticos.

\section{c. Créditos generalmente subordinados}

Esta tercera característica ofrece también una distancia con la subordinación voluntaria, que, conforme a los términos de los artículos 2489 CC y 241 LRLAEP, puede presentarse de modo general o particular. La diferencia entre una y otra categoría se encuentra especialmente en la identificación de los créditos que resultarán beneficiados por el hecho de la subordinación del crédito, lo que, en la lógica financiera, da cuenta,

${ }^{97}$ En este sentido, los artículos 57.1.c) y 264.4 LRLAEP requieren de la infracción de la protección financiera concursal dispuesta por la resolución de reorganización o de admisibilidad, según sea el caso. Respecto de la posposición de los créditos de las personas relacionadas al deudor, se fija como "periodo de sospecha” un término de noventa días previos al inicio del procedimiento de reorganización (artículo 63 LRLAEP) o a la dictación de la resolución de liquidación (artículo 241 LRLAEP). También se requiere de una resolución de liquidación para que se produzca la posposición de los intereses que se devenguen con posterioridad a su dictación (artículo 139 LRLAEP). Y, finalmente, solo la resolución que acoge una acción revocatoria concursal (artículo 292 LRLAEP), permite al tercero vencido verificar el crédito en el procedimiento concursal respectivo, pero sujeto a la posposición. 
a su vez, de una diversidad de propósitos y utilidades prácticas de la subordinación voluntaria ${ }^{98}$. Al contrario, todos los casos de subordinación legal se ofrecen como generales, en el sentido que serán todos los titulares de los créditos no subordinados los que recibirán los beneficios de la posposición legal, aumentando sus posibilidades de cobro ${ }^{99}$.

Debido a que se trata este de un efecto concedido por el legislador, no es posible participación de la voluntad de los particulares, en el sentido de alterar el efecto degradatorio asociado a la posposición crediticia, especialmente para escapar de sus consecuencias, por ejemplo, mediante la constitución de garantías reales sobre el patrimonio del deudor para obtener una preferencia ${ }^{100}$, o para limitar el beneficio a favor de un número limitado de créditos. Lo anterior tiene particular importancia en caso de coincidencia entre un supuesto de subordinación voluntaria particular (al amparo de lo que generalmente se conoce como un "acuerdo de subordinación") y uno de posposición legal. Si bien ha sido pretensión de las partes que la posposición de ciertos créditos solo beneficien a ciertos acreedores, dicha finalidad no se logrará en la confrontación de la norma legal que ordena la subordinación general. Lo anterior se justifica por una interpretación sistemática del ordenamiento, que concede a estas reglas de posposición un carácter de interés general, superando las pretensiones particulares de las partes a fin de asociar el carácter degradatorio del crédito a la consecución de las finalidades colectivas propias del concurso ${ }^{101}$.

Un último punto a considerar es la ausencia de reglas de graduación entre los diversos créditos subordinados, sea voluntaria o legalmente, lo que podrá generar dudas respecto de la forma de resolver la concurrencia de este tipo de créditos. Desde el punto de vista del Derecho comparado, la inclusión de los créditos subordinados en una categoría propia e independiente también resulta en una jerarquización ${ }^{102}$. Si bien esta inadvertencia por el legislador chileno no traerá mayores consecuencias, ya que resulta estadísticamente complejo que este tipo de créditos resulte efectivamente satisfecho en el marco del concurso, la necesidad de graduación ha respondido a la pretensión de los ordenamientos comparados de ofrecer, por una parte, una técnica similar a la que se establece en materia de privilegios crediticios, y, por la otra, una medida que da cuenta de los diversos méritos (o, mejor dicho, falta de méritos) en la comparación entre los diversos créditos subordinados, concediendo mayores argumentos para comprender su finalidad y justificación.

Así, en la única norma concedida en este punto por el Derecho chileno [artículo 57.1, c) LRLAEP], se advierte igual criterio, porque solo es posible comprender la mayor profundidad de la posposición del crédito infractor de la protección financiera concursal mediante un expediente sancionatorio del que, a nuestro juicio, carece aquella que se

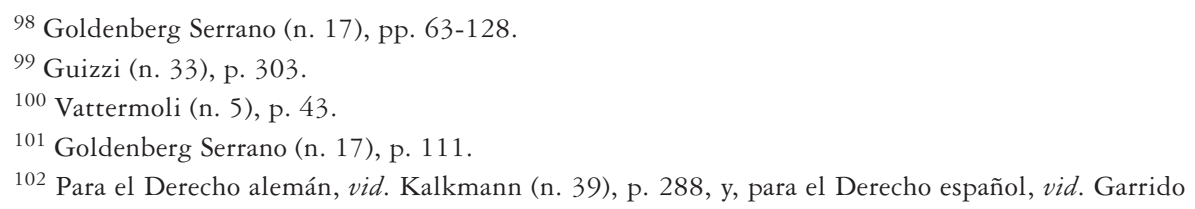


dispone para las personas relacionadas al deudor por la ausencia de documentación de su crédito en los noventa días previos a la dictación de la resolución de reorganización (artículo 63 LRLAEP). En los demás casos, sin embargo, la falta de una indicación clara concerniente al punto podrá provocar un debate, aunque es posible anticipar un tratamiento proporcional entre los diversos créditos, a fin de no crear jurisprudencialmente una regla de graduación allí donde el legislador la ha omitido.

\section{Conclusiones}

1. Como una de sus tantas novedades, la LRLAEP ha introducido la figura del crédito legalmente pospuesto, herramienta conocida en el Derecho comparado para completar el régimen de graduación de los créditos sobre la base de parámetros de justicia distributiva. De esta manera se refuerzan los intentos por ofrecer a los demás acreedores, principalmente los valistas, mejores perspectivas de satisfacción, pretendiendo alcanzar una mayor eficiencia del sistema concursal medida en razón de la tasa de recuperación de los créditos.

2. No obstante, nuestro ordenamiento no dispone de una categoría de créditos pospuestos y escasamente advierte los puntos de contacto con la subordinación voluntaria reconocida en el artículo 2489 CC. Lo anterior dificulta la comprensión de su naturaleza y régimen jurídico, a causa de que el elemento aglutinador parece estar únicamente dado por el deterioro en sus posibilidades de pago, el que solo podrá tener lugar una vez satisfechos los demás créditos concursales.

3. Desde la perspectiva de las reglas de prelación de crédito, parece indudable que la posposición ofrece una nueva regla de graduación, a modo de excepción negativa de la regla de reparto proporcional. Y, si bien existen elementos para completar su régimen desde la construcción de la noción de "privilegio" (en este caso, como "antiprivilegio"), las figuras no son completamente simétricas, aunque para su consagración el legislador no atiende únicamente a la naturaleza del crédito, sino también a conductas y elementos subjetivos y temporales. A su vez, la minusvaloración del crédito no puede observarse únicamente desde una finalidad sancionatoria, en la medida que no todos los supuestos pueden ser reconducidos a la idea de la penalidad civil. En consecuencia, las justificaciones del uso de la técnica de la subordinación legal deberán investigarse en cada uno de los tipos previstos por el legislador.

4. Ahora bien, desde el punto de vista de su régimen al interior del concurso, debemos destacar su carácter de crédito concursal, especialmente debilitado en lo que se refiere a su posibilidad de pago y en que se identifican como beneficiarios al resto de los créditos que conforman la masa pasiva. No obstante, la ausencia de una vinculación de estas características con el detrimento de otros derechos, especialmente políticos, puede ocasionar algunos problemas desde la lógica del conflicto de intereses. Ello si se considera que se tratará de créditos que, muy probablemente, no resultarán solucionados en el procedimiento concursal en particular. 


\section{BiBLIOGRAFÍA}

Abeliuk Manasevich, R., Las obligaciones, Tomo II (Sexta edición actualizada), Legal Publishing Thomson Reuters, Santiago, 2014, 1495 pp.

Alarcón Soto, A., La pena privada, Ediciones Jurídicas Santiago, Santiago, 2005, 156 pp.

Alemany Eguidazu, J., "Subordinación contractual y subordinación concursal", Diario La Ley, No 6004, Año XXV, 26 de abril de 2004, recurso electrónico.

Alessandri Rodríguez, A. La prelación de créditos, Editorial Nascimento, Santiago, 1940, 115 pp.

Alonso Ledesma, C., "Delimitación de la masa pasiva: las clases de crédito y su graduación", en García Villaverde, R., Alonso Ureba, A. y Pulgar Esquerra, J. (dirs.), Derecho concursal. Estudio sistemáticos de la Ley 22/2003 y de la Ley 8/2003 para la reforma concursal, Editorial Dilex, Madrid, 2003, pp. 357-407.

Ávila de la Torre, A. y Curto Polo, M., "La subordinación del crédito de las personas especialmente relacionadas con el concursado", en Estudios sobre la Ley concursal: Libro homenaje a Manuel Olivencia, T. IV, Marcial Pons, Madrid, 2005, pp. 3537-3567.

Ávila de la Torre, A., "La subordinación en el concurso de los créditos de las personas especialmente relacionadas", en Sarcina, A. y García-Cruces, J.A. (dirs.) Il trattamento giuridico della crisi d'impesa. Profili di diritto concorsuale italiano e spagnolo a confronto, Cacucci Editore, Bari, 2008, pp. 159-182.

Ávila de la Torre, A. "El pago de los créditos ordinarios y subordinados en la liquidación concursal”, en García-Cruces, J.A. (dir.) La liquidación concursal, Civitas Thomson Reuters, Cizur Menor, pp. 365-385.

Bahamóndez Prieto, L.F., La prelación de créditos, Editorial Jurídica de Chile, Santiago, 1993, 180 pp.

BAIRD, D. y Jackson, T.H., "Bargaining after the fall and the contours of the absolute priority rule”, University of Chicago Law Review, No 55, 1988, pp. 738-789.

Beltrán Sánchez, E., "El nuevo Derecho concursal español", Anales de la Academia Matrisense del Notariado, No 43, 2007, pp. 465-490.

Bermejo Gutiérrez, N., Créditos y quiebra, Civitas, Madrid, 2002, 572 pp.

BiAnCHI, A., Fucito, M. y Gulotta, M., Postergazione, prededucibilità e pagamento dei crediti in regime di continuità aziendale. Il finanziamenti societari nella legislazione sulla crisi di impresa, Maggioli Editore, Santarcangelo di Romagna, 2013, 322 pp.

Blasco Gascó, F. de P., El pago de los acreedores concursales, Aranzadi Thomson Reuters, Cizur Menor, 2010, 362 pp.

Bornemann, A., "\$39 InsO”, en Wimmer, K. (dir.) Frankfurter Kommentar zur Insolvenzordnung, Luchterhand Verlag, Colonia, 2013, pp. 621-629.

Cannada-Bartoli, E., “Affievolimento”, en Enciclopedia del Diritto, Tomo I, Giuffrè, Italia, 1958, pp. 670-671.

Contador Rosales, N. y Palacios Vergara, C., Procedimientos concursales, Thomson Reuters La Ley, Santiago, 2015, 366 pp.

Chaitman, H.D., "The equitable subordination of bank claims", The Business Lawyer, № 39, 1983-1984, pp. 1561-1572.

De Cicco, O., "Procedure concorsuali e par condicio creditorum: la protezione dei creditori tra parità e ragionevolezza", Rivista di Diritto dell'Impresa, No 2, 2011, pp. 343-356.

De la Cuesta Rute, J.M., El convenio concursal. Comentario a los artículos 98 a 141 de la Ley concursal, Thomson Aranzadi, Cizur Menor, 2004, 221 pp.

DíEz-Picazo, L. Fundamentos del Derecho civil patrimonial, T.I., Introducción. Teoría del Contrato, Thomson Civitas, Cizur Menor, 2007, 657 pp. 
Diurni, G., "Pena privata (dir. interm.)", en Enciclopedia del Diritto, T. XXXII, Giuffrè, Milán, 1982, pp. 739-752.

Eickmann, D., “\$39 InsO”, en Kreft, G. (dir.), Heidelberger Kommentar Insolvenzordnung C.F. Müller, Hamburgo, 2011, pp. 432-450.

Ferré Falcón, J., Los créditos subordinados, Thomson Civitas, Cizur Menor, 2006, 735 pp.

Ferri JR., G., "In tema di postergazione legale", Rivista del Diritto Commerciale e del Diritto generale delle obbligazioni, Año CII, Nos. 10, 11 y 12, 2004, pp. 969-1000.

García Orejudo, R., "Créditos subordinados", en Nieto Delgado, C. (coord.), Derecho concursal, Tirant lo Blanch, Valencia, 2012, pp. 471-495.

Garrido, J.M., Tratado de las preferencias del crédito, Civitas, Madrid, 2000, 813 pp.

Garrido, J.M., "Artículo 92. Créditos subordinados”, en Rojo, Á. y Beltrán, E. (dirs.) Comentarios de la Ley concursal, Thomson Civitas, Cizur Menor, 2004, pp. 1658-1668.

Goldenberg Serrano, J.L., "Consideraciones críticas respecto al denominado principio de la par condicio creditorum", Revista Chilena de Derecho, Vol. 37, N 1, 2010, pp. 73-98.

Goldenberg Serrano, J.L. La subordinación voluntaria de créditos, Civitas Thomson Reuters, Cizur Menor, $322 \mathrm{pp}$.

Goldenberg Serrano, J.L., "Bases para la privatización del Derecho concursal", Revista Chilena de Derecho Privado, No 20, 2013, pp. 9-49.

Goldenberg Serrano, J.L. "Justificación y fórmulas de protección al financiamiento de rescate", Revista de Derecho Privado (Universidad del Externado, Colombia), No 26, 2014, pp. 351-384.

Goode, R., Principles of corporate insolvency law, Sweet \& Maxwell, Londres, 2011, 835 pp.

Guilarte Gutiérrez, V., “Artículos $92.1^{\circ}$ a $4^{\circ}$ y 6 $6^{\circ}$, en Sánchez-Calero, J. y Guilarte Gutiérrez, V. (dirs.), Comentarios a la Legislación Concursal, T. II, Lex Nova, Valladolid, 2004, pp. 2026-2052.

Guizzi, G., "Il passivo", en Diritto Fallimentare (Manuale Breve), Giuffrè Editore, Milán, 2013, pp. 82-93.

Gullón Ballesteros, A. La prelación de créditos en el Código Civil, Bosch, Barcelona, 1962, 165 pp. Herzog, A. S. y Zwebel, J. B., "The equitable subordination of claims in bankruptcy”, Vanderbilt Law Review, Vol. 15, 1961-1962, pp. 83-118.

IвÁÑEZ Jiménez, J., "Deuda subordinada, obligaciones subordinadas y reforma concursal”, en Créditos, garantías y concurso. Estudios Jurídicos en Homenaje al Profesor Ruiz de Velasco, Civitas - Thomson Reuters, Cizur Menor, 2010, pp. 471-495.

Kalkmann, C., “\$39 InsO”, en Graf-Schliker, M.L. (dir.) InsO Kommentar, RWS, Colonia, 2012, pp. 287-307.

Locoratolo, S., Postergazione dei crediti e fallimento, Giuffrè Editore, Milán, 2010, 204 pp.

LÜDTKE, M., "§39 InsO”, en Hamburger Kommentar zum Insolvenzrecht, Carl Heymanns Verlag, Colonia, 2012, pp. 544-558.

Migliaccio, E., Parità de trattamento e concorso dei creditori, Edizioni Scientifische Italiane, Nápoles, 2012, 286 pp.

Montes Penades, V.L., "El régimen de los créditos subordinados en la Ley concursal", Anuario de Derecho Concursal, $\mathrm{N}^{\circ}$ 1, 2004, pp. 49-85.

Moscati, E., "Pena (dir. priv.)", Enciclopedia del Diritto, T. XXXII, Giuffrè, Milán, 1982, pp. $770-787$.

Puga Vial, J. E., Derecho concursal. Del procedimiento concursal de liquidación. Ley 20.72az0, Editorial Jurídica de Chile, Santiago, 2014, 694 pp.

Puga Vial, J.E., Derecho concursal. El acuerdo de reorganización, Editorial Jurídica de Chile, Santiago, 2014, 500 pp.

Sastre Papiol, S., “Artículo 92”, en Sagreda Tizón, J.M., Sala Reixacs, A. y Ferrer Barriendos, A., Comentarios a la Ley concursal, Bosch, Barcelona, 2004, pp. 1.130-1.139. 
SchmidT, K., "Fundamentos del nuevo Derecho concursal alemán", en García Villaverde, R., Alonso Ureba, A. y Pulgar Ezquerra, J. (dirs.), Estudios sobre el Anteproyecto de la Ley Concursal de 2001, Dilex, Madrid, 2002, pp. 15-39.

Schmidt, K. y Herchen, A., "\$39 InsO”, en Schmidt, K. (dir.), Insolvenzordnung, C.K. Beck, Munich, 2013, pp. 408-425.

Sebastián Quetglas, R. "La subordinación de los créditos en los grupos de sociedades", en Créditos, garantías y concurso. Estudios Jurídicos en Homenaje al Profesor Ruiz de Velasco, Civitas Thomson Reuters, Cizur Menor, 2010, pp. 443-470.

Troplong, M., Le Droit civil expliqué suivant l'ordre du code. Des priviléges et hypothèques, Vol. I, Sociètè Typographique Belgue, Bruselas, 1844, 470 pp.

Ugarte Godoy, J.J., "Sobre la posibilidad de pactar que una obligación tenga el carácter de subordinada en el Derecho chileno", en Varas Braun, J.A. y Turner Saelzer, S. (coords.), Estudios de Derecho Civil, Lexis Nexis, Santiago, 2005, pp. 373-389.

Valpuesta Gastaminza, E. “Artículo 92”, en Cordón Moreno, F. (dir.), Comentarios a la Ley concursal, Thomson Aranzadi, Cizur Menor, 2004, pp. 730-739.

VAnONI, S., I crediti subordinati, G. Giappichelli Editore, Turín, 2000, 272 pp.

VATtermoli, D., Crediti subordinati e concorso tra creditori, Giuffrè Editore, Milán, 2012, 487 pp.

Veiga Copo, A., La masa pasiva del concurso de acreedores, Civitas - Thomson Reuters, Cizur Menor, 1512 pp.

Vial del Río, V., Teoría general del acto jurídico, Editorial Jurídica de Chile, Santiago, 2003, 407 pp.

Warren, W.D., Bussel, D.J. y Skeel, Jr., D.A., Bankruptcy, Foundation Press, Estados Unidos de América, 957 pp.

Wood, P.R., The law of subordinated debt, Sweet \& Maxwell, Londres, 1990, 247 pp. 